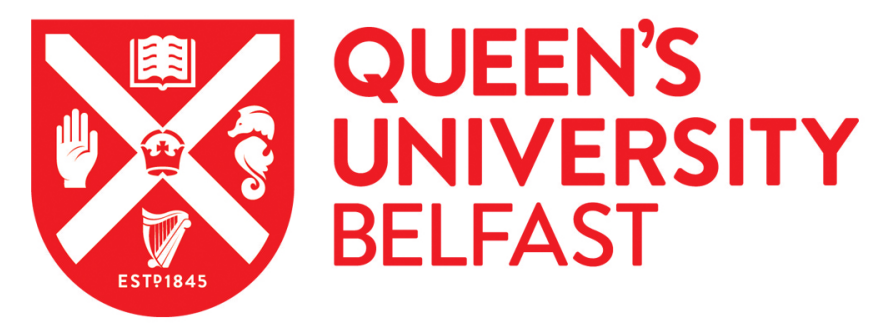

\title{
Navigating Risk: Understanding the Impact of the Conflict on Children and Young People in Northern Ireland
}

Browne, B., \& Dwyer, C. (2014). Navigating Risk: Understanding the Impact of the Conflict on Children and Young People in Northern Ireland: Special Issue: Northern Ireland: 20 Years After the Cease-Fires. Studies in Conflict and Terrorism, 37(9), 792-805. https://doi.org/10.1080/1057610X.2014.931213

Published in:

Studies in Conflict and Terrorism

Document Version:

Peer reviewed version

Queen's University Belfast - Research Portal:

Link to publication record in Queen's University Belfast Research Portal

Publisher rights

This is an Accepted Manuscript of an article published by Taylor \& Francis in Studies in Conflict \& Terrorism on 16 June 2014, available online: http://www.tandfonline.com/doi/abs/10.1080/1057610X.2014.931213

\section{General rights}

Copyright for the publications made accessible via the Queen's University Belfast Research Portal is retained by the author(s) and / or other copyright owners and it is a condition of accessing these publications that users recognise and abide by the legal requirements associated with these rights.

Take down policy

The Research Portal is Queen's institutional repository that provides access to Queen's research output. Every effort has been made to ensure that content in the Research Portal does not infringe any person's rights, or applicable UK laws. If you discover content in the Research Portal that you believe breaches copyright or violates any law, please contact openaccess@qub.ac.uk. 


\title{
FINAL AUTHOR VERSION \\ Published version: Studies in Conflict and Terrorism (2014) 37:792-805
}

Address correspondence to Clare Dwyer, School of Law, Queen's University Belfast, 27-30

University Square, Belfast BT7 1NN, Ireland. E-mail: c.dwyer@qub.ac.uk

\section{Navigating Risk: Understanding the Impact of the Conflict on Children and Young People in Northern Ireland}

\author{
BRENDAN BROWNE \\ CLARE DWYER \\ School of Law \\ Queen's University Belfast \\ Belfast, Ireland
}

20 years on from the 1994 ceasefires, Northern Ireland is a markedly safer place for children and young people to grow up. However, for a significant number, growing up in post-conflict Northern Ireland has brought with it continued risks and high levels of marginalization. Many young people growing up on the sharp edge of the transition have continued to experience troubling levels of poverty, lower educational attainment, poor standards of childhood health and sustained exposure to risk laden environments. Reflecting upon interdisciplinary research carried out since the start of the 'transition' to peace, this paper emphasizes the impact that embedded structural inequalities continue to have on the social, physical, mental and emotional well-being of many children and young people. In shining a light on the enduring legacy of the conflict, this paper moves to argue that greater attention needs to be given to the ongoing socio-economic factors which result in limited lifetime opportunities, marginalization and sustained poverty for many young people growing up in 'peacetime' Northern Ireland.

As Northern Ireland enters its $20^{\text {th }}$ year since the pivotal 1994 paramilitary ceasefires, this is a fitting time to take stock of the progress that has been made and to assess the evolvement from seemingly intractable conflict to relatively peaceful co-existence. However, shining a light on progress exposes from the shadows the residual negative impact the conflict continues to have on certain populations, including children and young people. Whereas 20 years on from the ceasefires, Northern Ireland is a markedly safer place in which to grow up, ${ }^{1}$ for a significant number of those living on the sharp edge of the transition, particularly marginalised or 'at risk' children and young people, the everyday lived experience of growing up in post-conflict Northern Ireland is less optimistic. Troubling levels of childhood poverty, lower educational attainment, poor standards of childhood health, sustained exposure to risk laden environments, including ad hoc experience of inter community violence have become daily norms filling the risky void in which the ethnosectarian conflict once operated. Although, the 1998 Belfast/Good Friday Agreement created the 
opportunity for a more stable and peaceful Northern Ireland, for a significant number of children and young people, this transition to peace has brought further marginalisation, increased social exclusion and exposure to hazardous environments. ${ }^{2}$ All of which leads to the suggestion that, despite the absence of violent political conflict, for some growing up in the 'new' Northern Ireland remains both challenging and dangerous.

Reflecting upon the existing literature which has taken as its focus the impact of the conflict on childhood development in Northern Ireland, we will argue that growing up during this transitional period poses additional challenges, concluding that for many 'at risk' or marginalised youth the very notion of a post-conflict or transitional Northern Ireland is moot. The risk factors associated with growing up during intense periods of the conflict itself have been documented and explored extensively in the literature. ${ }^{3}$ Notwithstanding the importance of research thus far which highlights the on-going impact of growing up amidst sporadic inter community violence, residential segregation, or exposure to paramilitarism, we echo the views of earlier research on Northern Irish youth cultures ${ }^{4}$ and argue that these issues continue to be grounded in deeply embedded structural problems including life opportunities and poverty.

Discussions that frame the lives of children and young people growing up in Northern Ireland primarily in terms of their fears surrounding inter community violence with the perceived 'other' mask the underlying social problems that the post-agreement era has failed to take hold of (despite continuous policy attempts), including inter alia: high levels of childhood poverty, high rates of drug/substance abuse amongst marginalised youth, and lower levels of educational attainment, many of which can be linked to childhood depression or poor mental health. On Monday $17^{\text {th }}$ June 2013, President Obama addressed a packed Waterfront Hall in Belfast's much transformed city centre. Just over 2000 audience members, including many school children, listened on as the President spoke of the great strides Northern Ireland has made and the enduring legacy of the peace process on the lives of children and young people growing up in the region.

... while you have unique challenges of your own, you also have unique reasons to be hopeful. For you are the first generation in this land to inherit more than just the hardened attitudes and the bitter prejudices of the past. You're an inheritor of a just and hard-earned peace. You now live in a thoroughly modern Northern Ireland (Barack Obama, June 2013, Waterfront Hall Belfast) ${ }^{5}$

The President also spoke of choice, calling on young people to choose peaceful pathways in their transitions into adult life as opposed to returning to the violence of the past. However, for many the possibility of choice is absent from their daily lives. At the time of this presidential visit, the authors were undertaking research with young people growing up in some of the most marginalised communities in Belfast ${ }^{6}$. This ongoing research is part of a unique long-term longitudinal study funded by the USA National Institutes of Health (NIH), and the Office of First Minister and Deputy First Minister (OFMDFM), Northern Ireland. The primary concern of the study is a multi-faceted 
assessment of the inter-connected relations between sectarian conflict and violence and family and community life in Belfast, including the social needs, mental health and good relations between Catholic and Protestant youth in deprived areas of Belfast. The project includes quantitative surveys with mothers and children and qualitative focus groups and semi-structured interviews with children and young people. Although this research is ongoing, it is apparent that growing up in a post conflict society continues to have significant impact on the lives of young people, particularly in regards to their well-being, lifetime opportunities and mental health. In particular, findings demonstrate high levels of emotional and mental health issues including a prevalence of low self-esteem, an appreciation and knowledge of self-harm and/or suicide and high levels of alcohol and substance misuse.

Although it is not our intention to detail our findings here, it is useful for the purpose of this paper to highlight that one of the key insights emanating from this current research is that the children and young people in the sample were more likely to suffer physical/verbal/emotional abuse from members of their 'own' community as opposed to members of the 'other' community, leading to the suggestion that actual risk from within is more pronounced than the perceived risk from the outside. This is important, not least because the aim of this paper is to evaluate the continued risks that young people growing up in Northern Ireland have had to endure since the 'formal' cessation of paramilitary activity in 1994. We argue, as others have in recent times ${ }^{7}$ that the residual impact of the conflict on the lives of young people growing up during this so-called period of transition is an escalation in poor childhood mental health, with research pointing to higher levels of childhood depression and suicide throughout Northern Ireland. ${ }^{8}$ However, we move to suggest that by shining a light on the residual impact of the conflict, it is apparent that greater attention needs to be given to on-going and continued structural inequalities including poverty and limitations to lifetime opportunities that children growing up in some of the most marginalized communities experience in their daily lives.

\section{The Challenges of 'Transition within Transition' and the Interpretation of Risk}

Considered to be one of the most important issues in any post-conflict period of reconstruction, the impact of the "troubles" has been most acutely felt by vulnerable or 'at risk' groups, including children and young people. Cummings et. al. ${ }^{9}$ note that;

The effects on children of political violence are matters of international concern, with negative outcomes...including heightened aggression and violence, anxiety, depression, post-traumatic stress, somatic complaints, poor school performance, and engagement in political violence. ${ }^{10}$

International research conducted in other conflict-impacted regions suggests that adverse childhood experiences, particularly those gained during a period of wartime instability and

protracted conflict, can lead to health (including mental health) problems in adult life. ${ }^{11}$ Other 
studies in conflict or post-conflict regions ${ }^{12}$ argue that regardless of whether or not children and young people are directly exposed to traumatic events, very few are 'spared the osmotic effects of the militarization of the society as a whole.' 13 In Northern Ireland, children and young people face a higher risk (almost 25\% higher than the UK average), of having mental ill health, ${ }^{14}$ a fact that is considered linked to the increased risk factors which children and young people are forced to negotiate during their transition to adulthood whilst living in a society moving away from serious conflict. ${ }^{15}$

Interpretations of risk have readily been used by social scientists involved in primary research on issues related to mapping childhood development and the transition from adolescent to adult life. Scholars have found the term a particularly useful lens through which to measure the challenges related to adolescent transition towards adult life, and the concomitant dangers associated therein. As a term with interdisciplinary appeal ${ }^{16}$, 'risk' has been subjected to the widest possible interpretation, with Dwyer suggesting, '(risk)...is a more heterogeneous concept than is sometimes acknowledged.' 17 Further interpretations have noted the term is used to 'denote a phenomenon that has the potential to deliver substantial harm, whether or not the probability of this harm eventuating is estimable.' 18

The transition of western societies towards a post-modern, 'risk-laden' environment ${ }^{19}$ has brought with it additional hurdles that young people seek to successfully navigate in a challenging period of transition and in moving from adolescent dependency to adult independence. ${ }^{20}$ This period of growth and development presents young people with choices to make, with the journey into adulthood involving a wide variety of routes, many of which appear to have uncertain outcomes. $^{21}$ These uncertain outcomes, however, are often unevenly felt and links have been drawn between successful navigation of societal risk and socio-economic position of a child or young person within society. ${ }^{22}$ Marginalised or 'at risk' children and young people are often confronted with additional uncertainty which is linked to their level of social exclusion, ${ }^{23}$ lack of disposable income, or as a result of the socio-economic status of the areas in which they grow up. It is argued that these 'structural determinants and manifestations of social exclusion, political disillusionment and economic marginalisation, ${ }^{24}$ are amongst just some of the risks faced by societies most vulnerable and marginalised young people. So to Schoon ${ }^{25}$ who concludes:

Children reared in deprived or disadvantaged circumstances are at increased risk of adverse developmental outcomes ranging from educational underachievement and behavioural problems to adjustment problems in later life, such as low occupational status and poor health. ${ }^{26}$

Whereas these risks may be shared by marginalised children and young people growing up in the rest of the United Kingdom, the residual impact of living in a post-conflict environment adds an additional layer of risk to a young person's already uncertain move towards adulthood. Numerous studies have found that exposure to sporadic acts of inter-community violence, the threat of paramilitary recruitment, the impact of residential segregation, the negotiation of risky 
spaces and dangerous interfaces, all remain significant impacting factors in the daily lives of children and young people in Northern Ireland. ${ }^{27}$ Although Northern Ireland has witnessed an end to the conflict, for many children and young people, growing up in a post conflict society remains a challenging prospect.

\section{Exposure to Conflict-Related Violence and the Navigation of Risks}

As a society characterised by division in terms of spatial residence, education, and community interaction, the lives of young people continue to be influenced as a direct result of the legacy of the conflict. Exposure to conflict related violence and the subsequent impact this has on children's lives has been a central concern for research emanating from Northern Ireland. ${ }^{28}$ Many researchers espouse the view that one should assess the effect of sustained violence and disruption on the lives of children and young people in order to garner a deeper understanding of the lasting impact of conflict in general. ${ }^{29}$ Various studies focus on the nature of violent incidents children and young people are regularly exposed to, including witnessing conflict-related violence first hand, hearing about the violent act, and/or being exposed to violence through alternative outlets such as the media. ${ }^{30}$ The likelihood of childhood exposure to personal physical harm or secondary trauma through loss of a loved one has been the subject of interdisciplinary scholarly analysis. It has been recorded that the number of young people (18 years of age and under) killed during the period 1969- 2003, as 274, with an additional 629 people aged between 18 and 21 killed $^{31}$. Hansson $^{32}$ draws attention to the impact that the conflict had on children and young people by outlining that almost a third (32\%) of 14-18 year olds growing up during 'the troubles' witnessed someone being killed or seriously injured. Studies have noted that the likelihood of experiencing such traumatic events or being exposed to the risk of such an eventuality occurring was heavily dependent upon a number of additional and at times interlinked factors, including one's socioeconomic status, religion, neighbourhood, and gender. ${ }^{33}$

As active participants, young people, and in particular young men, played a prominent role in inter-community and paramilitary violence. Many of these active participants grew up in urban areas of Belfast and Derry/Londonderry and came from lower socio-economic backgrounds. ${ }^{34}$ Similarly, young men were more likely to be 'at risk' from sectarian incidents or attacks. ${ }^{35}$ With the onset of peace and transition away from conflict, the risk of serious harm as a result of conflict related violence has unsurprisingly diminished with the number of childhood (18 years and under) fatalities since 1994 dropping to $22 .{ }^{36}$ As such, there no longer exists a tangible risk of death or serious injury from political violence, despite the on-going inter-community conflict that flares up at designated times throughout the year.

Notwithstanding the relative absence of conflict-related violence, children and young people growing up in Northern Ireland continue to be exposed to high levels of violence. Findings published in the 2006/2007 Northern Ireland Crime Survey reveal that children and young people continue to experience violent incidents, be exposed to violent scenarios, or engage in violent 
activity, more so than their adult counterparts and particularly in areas where social deprivation remains high. ${ }^{37}$ In Northern Ireland, violent incidents recorded are regularly sub-categorised as either 'normal' and/or 'sectarian', a distinction which, Jarman ${ }^{38}$ argues, is difficult to make. Nevertheless, the point remains that children and young people are most 'at risk' of experiencing serious and violent crime, some of which it can be argued will be conflict related.

Other research studies have focussed on issues related to transferred trauma, analysing the indirect impact of violence and assessing whether children and young people born into a culture of violence could themselves be affected. In the immediate aftermath of the 1994 paramilitary ceasefires, research found that children and young people could become traumatised as a result of bearing 'witness (to)...violent events indirectly... listening to others talk about violence, ... or know relatives who have been traumatized. ${ }^{39}$ Ten years later in 2004, research found that this trans-generational trauma continued to impact on 'children's education, their mental health and their ability to participate in society. ${ }^{40}$ Other studies point to a potential intergenerational knowledge transfer of conflict related incidents, noting that interactions between children and adult victims of conflict related violence can lead to a continuation in 'the social and psychological legacy of the "Troubles". ${ }^{41}$ More recent data presented on young people's trans-generational issues reported that young people sampled found that 'the troubles related experiences of their families had a greater impact on them than the troubles related events they had personally experienced.' 42

\section{Navigating Risky Environments: Peace-walls, Paramilitaries and Poverty}

As noted, for a significant number of children and young people growing up in Northern Ireland, living in segregated communities is their normality and Belfast, as the capital city, provides a visible example of this everyday residential segregation. Since the 1994 ceasefires, Belfast has witnessed an increased presence of 'peace-walls' and separation fences (also referred to as interfaces) designed to keep the two dominant communities living in the city spatially segregated. ${ }^{43}$ These interface areas, have become significant physical boundaries in a young person's life and assume great importance in terms of identity construction. ${ }^{44}$ Connolly and Healy ${ }^{45}$ argue that children as young as 10 years of age have a strong sense of attachment to their separate areas and are aware of the risks posed by venturing beyond these boundaries. Interface areas are considered places 'within which fear and avoidance of the ethnic "other" are commonplace and daily occurrences.' 46

Young people's management of what Leonard ${ }^{47}$ refers to as 'sectarian space' is an important contributory factor to the risks associated with growing up in post-conflict Belfast. Negotiating safe and risky spaces has become commonplace for a growing number of urban youth. ${ }^{48}$ Leonard's work on young people's decision making and risk management on the interface has shown that 'teenagers negotiate movement across different types of space... their immediate geographical environment is dependent on its location within wider political, social and cultural 
systems. ${ }^{49}$ Leonard's ${ }^{50}$ focus on risky environments has revealed that children and young people growing up alongside or nearby one of Belfast's ever expanding interface areas experience problems on a daily basis related to their personal safety.

Other research has focussed on drawing links between residential segregation, interface areas, and youth experience of violence. This experience of engaging in predominantly low-level violence includes inter-community conflict with children and young people from the 'other' side and exposure to paramilitary activity. Research has shown that those living in close proximity to an interface continue to engage in ad hoc outbreaks of violence, particularly at certain moments throughout the year, i.e. the marching season in the summer months. ${ }^{51}$ Far from being merely 'something to do' when bored, research has found that young people's participation in this activity 'was imbued with political undertones. ${ }^{52}$ Findings from Leonard's research with a crosscommunity sample of Belfast teenagers challenge the view that engagement in this form of antisocial behaviour was apolitical. Use of the term 'recreational' was significantly disputed by views expressed by the young people in her research. What often starts as little more than 'abusive banter among relatively young children ${ }^{53}$ has the potential to escalate into serious skirmishes, with the police force becoming the shared target on both sides. Therefore, this form of violent activity more often than not has core latent sectarian undertones.

Experiencing and exposure to such events is often accompanied with feelings of fear, mistrust, anxiety, stress, and worry amongst children and young people living near or alongside interface areas which has undoubtedly impacted upon the mental well-being of those young people affected. Other studies have attempted to document the on-going impact of exposure to paramilitary groups as custodians of justice in the community. Despite the formal 'cessation of operations', paramilitary groups continue to have an omnipresent position in many communities across Northern Ireland. In recent times, there has been an increase in paramilitary style policing including attacks and intimidation, particularly against young people in various communities. Research points to continued paramilitary style attacks and the associated threat to the well-being of children and young people, as well as the continued paramilitary recruitment of youth. Smith ${ }^{54}$ argues there exist complex and ever changing opinions among young people towards paramilitaries in their area, the threat they pose to their community, and the risks associated with becoming involved in paramilitary activity.

Notwithstanding the findings of important research studies that highlight young people's negative views on paramilitary groups, believing them to arbitrarily punish young people for perceived anti-social behaviour, ${ }^{55}$ other work suggests that certain young people view the groups 'as cool, having status and being potential role models for young people'. ${ }^{56}$ Harland's ${ }^{57}$ in-depth analysis of marginalised young men (aged 13-16) and in particular their experience of paramilitary activity and perception of paramilitarism points to a mixed attitude to their presence in the community. Despite high levels of negativity (with 90\% of those interviewed living in fear of paramilitary violence), paramilitary involvement was considered an inevitable risk of growing up in certain areas. 
When combined with a range of other factors, including poverty, inequality, social exclusion, or disillusionment with the post-conflict environment, the risks associated with becoming involved with paramilitary groups were not readily considered, with the result being a greater propensity or likelihood to become involved in political violence. ${ }^{58}$ Perhaps unsurprisingly, areas which have been categorised as most socially deprived are also places where children and young people risk being exposed to serious outbreaks of political violence. As McAloney et. al. ${ }^{59}$ have suggested, 'research consistently identifies strong links between neighbourhood disadvantage and participation in or exposure to violent or criminal acts'. Muldoon ${ }^{60}$ notes that 'deep social divisions generally accompany political violence; most areas of conflict are particularly affected by other social ills such as poverty, deprivation, sectarianism, or racism.' Recent research conducted by Hargie et. al. ${ }^{61}$ outlines that young people living in areas of high social deprivation 'are at the cutting edge of the divisions that have blighted Northern Ireland.' Commonly held assumptions such as the chronic shortage of employment opportunities for young people living in 'ghettoized' communities, lack of educational attainment, poor family structure are often cited as important reasons as to why young people feel socially excluded. ${ }^{62}$

Links between poverty, low educational attainment, social deprivation and poor mental health have been well documented in academic research and governmental policy papers. ${ }^{63}$ Recent research published by Save the Children ${ }^{64}$ outlined that more than 1 in 4 children in Northern Ireland live in poverty (almost double the UK average), with 1 in 10 living in extreme poverty. Hillyard, et. al. ${ }^{65}$ outline that there exists 'a strong, but complex, relationship between poverty and conflict.' The argument advanced by a number of scholars is that by living in these areas young people are at risk of being socially excluded and removed from the benefits of living in Northern Ireland's transition away from conflict.

\section{Growing up in Northern Ireland: 20 Years after the Ceasefires}

As has been documented above, there exists a vast array of literature that has sought to analyse the impact of the conflict upon the lives of children and young people growing up in Northern Ireland. Studies have focussed on the impact of community segregation, on-going sporadic acts of intercommunity violence, exposure to paramilitary groups, to name only a few. Much of the research demonstrates that for many children and young people 'the notions of 'post conflict' or 'transition' are distant possibilities as sectarianism entrenches hatred for the 'other', physically as well as psychologically and culturally. ${ }^{66}$

Research has continued to highlight the residual impact of the conflict, specifically in relation to continued segregation and division between communities. In 2011 the Belfast Interface Project released findings which noted an incremental rise in 'peace walls' (from 88 to 99) between 2008- 2011. ${ }^{67}$ More recent figures published in 2013 illustrate the continued impact of residential segregation and points to the continuous rise in the building of the somewhat oxymoronic 'peace walls'. ${ }^{68}$ Evidently, post-conflict Northern Ireland continues to be an environment in which segregation and division between the two main communities remains a key feature and that 
children born in these areas subsequently suffer the effects of limited contact with their neighbours, fear and suspicion being the residual effects of communal division from such a young age.

But what of 'non-conflict' related risks associated with childhood transition in Northern Ireland? Analysis of policy reports, including The Northern Ireland Peace Monitoring Report, The 10 Year Strategy for Children and Young People, 'Our Children and Young People-Our Pledge', Lifetime Opportunities (LTO) - Anti-Poverty and Social Inclusion Strategy, to name only a few, draw attention to other factors that impact on the well-being of children and young people, including levels of childhood poverty, youth unemployment, educational achievement, and wellbeing and (un)happiness.

With regard to levels of social deprivation and economic hardship, alarmingly a number of areas in Northern Ireland rank amongst the top twenty highest in terms of levels of childhood poverty in the United Kingdom. Data collected and interpreted from tax records in February 2013 revealed that the parliamentary constituency of West Belfast ranks second highest behind Manchester Central in terms of childhood poverty. ${ }^{69}$ When one considers the link between social deprivation and other factors such as educational attainment, youth employment, and social exclusion, it follows that marginalised young people growing up in Northern Ireland continue to negotiate risk and uncertainty in their everyday lives despite the reduction in serious ethnosectarian conflict. ${ }^{70}$

Despite having areas ranking amongst the highest in terms of economic deprivation and childhood poverty in the UK, Northern Ireland will be unable to avoid the impact of financial cut backs to the Welfare Reform Bill. Notwithstanding political protestation, it is likely that $£ 600$ million will be shaved from the $£ 4$ billion Welfare bill. ${ }^{71}$ As is consistent across the United Kingdom, the cuts will disproportionately attack those already suffering marginalisation, primarily children and young people from socially deprived backgrounds, making the move from adolescence into adulthood increasingly uncertain and risky. Furthermore, the inequality gap between the richest and poorest in society will continue to increase. It is hard to see how any reduction in welfare will avoid further increasing childhood unemployment and thus poverty, all of which will most likely impact upon the lifetime opportunities, well-being and mental health of children and young people throughout Northern Ireland.

In considering educational attainment, children and young people in Northern Ireland generally out perform their counterparts in England, Scotland and Wales in terms of academic achievement overall (including General Certificate in Secondary Education (GCSE) results, and A-Levels). However, when one considers the link between socio-economic status and educational attainment, a more worrying trend emerges. Using evidence of children and young people entitled to free school meals (FSM) as a suggested poverty indicator, it is noted that those not entitled to FSM outperform those who are and by some distance. Put simply, those from lower socioeconomic backgrounds consistently fail to perform well in terms of academic achievements. Furthermore, it has also emerged that almost half of all Catholic girls growing up in lower socioeconomic backgrounds go on to higher education, whereas less than a third of Protestant boys from similar backgrounds do. ${ }^{72}$ Additionally, 7 out of the top 10 areas of lowest educational attainment 
are classified as Protestant. ${ }^{73}$ When you consider the potentially significant effect that this has on lifetime opportunities for children and young people growing up in Northern Ireland it is worth analysing youth unemployment figures and comparing them to the rest of the United Kingdom. Statistics released in 2013 point to an increase in the number of young people seeking work, with Catholics worse off than their Protestant counterparts. However, a more worrying trend developing is the growing number of young people between the ages of 16- 24 years not in education, employment or training (NEETs). This figure sits at 22.6\% (2\% higher than the overall UK average) and will continue to rise amidst this period of economic austerity.

When these data are taken together, evidence of a vicious cycle for children and young people growing up in certain parts of Northern Ireland becomes apparent. A significant section of children and young people are born into economic hardship primarily in areas scarred by the legacy of a political conflict. Their lower socio-economic position has the potential to impact on their ability to negotiate the traditional risks associated with adolescent transition into adult life. Many of them, understandably, are unable to do so. The most socially deprived areas in Belfast are also areas where 'peace walls' or interfaces between communities are prominent, are areas of lowest educational attainment with the fewest amount of children and young people progressing into third level education, and are places where youth unemployment runs highest. The deleterious impact that (un)successful negotiation of these risk factors, and the attendant hardship for children and young people, particularly on their mental health and well-being, must thus be considered a major cause for concern.

In 2012, the Office of National Statistics (ONS) commissioned a study that sought to garner deeper understanding on the wellbeing of the UK population. ${ }^{74}$ Northern Ireland scored particularly well, with the most optimistic and positive comments coming from children and young people aged between 16- 19 years. However, despite this positive feedback, Northern Ireland has witnessed a sharp increase in the level of suicide, with young males at the highest risk. Recent research conducted by Tomlinson ${ }^{75}$ points to the onset of peace, and the absence of violence, to account for this alarming increase. Whereas before externalized male aggression was more socially acceptable, internal feelings of guilt, shame and social isolation have subsequently resulted in a rise in male suicide. ${ }^{76}$ The recently commissioned cross-border study entitled Young Men and Suicide highlighted that the number of people, in particular young men, taking their own lives in Northern Ireland has risen from 159 in 2001, to 313 in 2011. This dramatic rise has seen Northern Ireland go from having the lowest to the highest rate of suicide in the UK. Nolan ${ }^{77}$ sheds further light on this worrying trend, commenting: 'For the past two years there have been about five times as many suicides as fatal road accidents - despite an investment of over $£ 32$ million in suicide prevention since 2006.' In addition, the number of young people taking anti-depressants has dramatically increased in recent years, all of which paints a rather bleak picture on growing up in Northern Ireland. Moreover, there is a paucity of information that has examined the efficacy and youth uptake of mental health provisions available. Haydon and Scraton ${ }^{78}$ highlight this problematic: 
Across Northern Ireland, over 20 per cent of children under 18 suffer significant mental health problems... [yet]... despite forming 25 per cent of the population, under 18's receive less than 5 per cent of the mental health budget.

Recent findings have confirmed that young people continue to experience serious issues when accessing mental health provisions. Hanna et al. found that many young people are unaware of various mental health service provisions and reported that even if more information were provided, many of the young people in the study would be reluctant to avail of such services. This research found that young people:

'may be deterred from accessing such services due to the worry it may affect their future careers, feelings of embarrassment, a belief that counselling is ineffective and a belief that they should be able to deal with their problems themselves. ${ }^{, 79}$

It is apparent that this is an area which needs further investment as the provisions that are in place to assist young people in coping with the challenges associated with growing up in this period of transition are chronically lacking.

\section{Conclusion}

Nearly 30 years ago, during one of the worst periods of the conflict, Bell found that:

... young people themselves are experiencing a specific material situation. This is the generation whose birth coincided with the onset of the 'troubles'. The ghettoization of residential life since then has affected them perhaps more than any other age group. Their physical mobility is restricted as are their opportunities ... ${ }^{80}$

In the period since the pivotal ceasefires which led the way for peace, it is clear that many young people continue to experience a very 'specific material' situation. The young people of 2013 are a generation whose birth coincided with the onset of the peace process and the signing of the peace agreement. However, many continue to experience restricted opportunities as a result of sustained 'ghettoization', social and material deprivation. As many children and young people attempt to navigate their way through the various risks in a transitional society, it is evident that a sizeable number still endure the impact of the conflict and have experienced detrimental effects on their lifetime opportunities and overall well-being. Therefore, despite living in a 'post' conflict society, much research has concluded that growing up remains both challenging and dangerous.

Notwithstanding the importance of research thus far which highlights the on-going impact of growing up amidst sporadic inter community violence, residential segregation, or exposure to paramilitarism, we echo the views that these issues continue to be grounded in deeply embedded 
structural problems. ${ }^{81}$ As noted, discussions that frame the lives of children and young people growing up in Northern Ireland primarily in terms of their fears surrounding inter community violence with the perceived 'other' mask the underlying social problems that the post-agreement era has failed to take hold of, including, but not limited to, lower levels of educational attainment, high rates of drug/substance misuse amongst marginalised young people, and high levels of childhood poverty and social deprivation. Gandhi once stated that "poverty is the worst form of violence" ${ }^{82}$ thus recognizing poverty to be the root of all ills and the reason why progress cannot be made. Poverty, like conflict, injures people by subjecting them to a general restriction of their human potential. Many communities across Northern Ireland face the same socio-economic struggles today, which were experienced before and throughout the conflict. Therefore, further focus is needed on developing a better understanding of what growing up in the 'new' Northern Ireland really represents, particularly amongst those children and young people who are living in communities experiencing high levels of social deprivation and hence are situated at the sharp edge of Northern Ireland's transition. 


\section{Notes}

${ }^{1}$ C. Coulter and M. Murray, Northern Ireland After the Troubles: A Society in Transition (Manchester: Manchester University Press, 2008).

${ }^{2}$ O. Hargie, A. O’Donnell, and C. McMullan, "Constructions of Social Exclusion among Young People From Interface Areas of Northern Ireland,” Youth \& Society 43(3) (2011), pp. 873- 899; D. Haydon and P. Scraton, "Conflict, Regulation and Marginalisation in the North of Ireland: The Experiences of Children and Young People,” Current Issues in Criminal Justice 20(1) (2008), pp. 59-78; S. McAlister, "Predictable Pathways? Negotiating Risk in the Context of Marginalisation and Social Exclusion,” Current Issues in Criminal Justice 20 (2008), pp. 14-27; S. McAlister, P. Scraton, and D. Haydon, Childhood in Transition: Experiencing Marginalisation and Conflict in Northern Ireland (Belfast: Save the Children and The Princes Trust, 2009). Available at http://www.savethechildren.org.uk/resources/online-library/childhood-transitionexperiencing marginalisation-and-conflict-northern (accessed 21 July 2014).

${ }^{3}$ L. McWhirter, “Northern Irish Children's Conceptions of Violent Crime,” Howard Journal 21 (1982), pp. 167-177; O. Muldoon, K. Trew, and R. Kilpatrick, "The Legacy of the Troubles on the Young People's Psychological and Social Development and their School Life," Youth \& Society 32(1) (2000), pp. 6-28; M. Leonard, M. McKnight, and S. Spyrou, "Growing up in Divided Societies: Confronting Continuity and Change,” International Journal of Sociology and Social Policy 31(9) (2011), pp. 520-530; E. Werner, "Children and War: Risk, Resilience, and Recovery,” Development and Psychopathology 24 (2012), pp. 553-558; F. Moughrabi, A Nation at Risk: The Impact of Violence on Palestinian Children (Ramallah: Qattan Center for Educational Research and Development, 2001).

${ }^{4}$ D. Bell, Acts of Union: Youth Culture and Sectarianism in Northern Ireland (London: Macmillan, 1990). Peter Shirlow and Brendan Murtagh, Belfast: Segregation, Violence and the City (Manchester: Manchester University Press, 2006); Peter Shirlowand Mark McGovern, "Sectarianism, Socioeconomic Competition and the Political Economy of Ulster Loyalism," Antipode 28(4) (1996), pp. 379-398.

5 Barack Obama, June 2013, Waterfront Hall Belfast. Available at http://iipdigital. usembassy.gov/st/english/texttrans/2013/06/20130617276442.html\#axzz2WYmhZUNb (access 21 July 2014).

${ }^{6}$ Growing up on an Interface: Findings and Implications for the Social Needs, Mental Health and Lifetime Opportunities for Belfast Youth (with P. Shirlow, Queens University Belfast; M. Cummings and C. Merrilees, Notre Dame University), funded by National Institute of Health (USA) and OFM/DFM.

${ }^{7}$ E. Gallagher, B. Hamber, and E. Joy, "Perspectives and Possibilities: Mental Health in postAgreement Northern Ireland," Shared Space: A Research Journal on Peace, Conflict and Community Relations in Northern Ireland (Belfast: Community Relations Council, 2012).

${ }^{8}$ K. McAloney, P. McCrystal, A. Percy, and C. McCartan, "Damaged Youth, Prevalence of Community Violence Exposure and Implications for Adolescent Well-Being in Post-Conflict Northern Ireland,” Journal of Community Psychology 37 (2009), pp. 635-648; G. McDonald, N. Livingstone, G. Davidson, S. Sloan, F. Montserrat, and D. McSherry, "Improving the Mental Health of Northern Ireland's Children and Young People: Priorities for Research," Institute of Childcare Research, Queen's University Belfast (2011, November); M. Tomlinson, "War, Peace, and Suicide:The Case of Northern Ireland,” International Sociology 27(4) (2012), pp. 464-482 
${ }^{9}$ M. E. Cummings, C. E.Merrilees,A. C. Schermerhorn, M. C. Goeke-Morey, P. Shirlow, and E. Cairns, "Longitudinal Pathways Between Political Violence and Child Adjustment: The Role of Emotional Security and the Community in Northern Ireland," Journal of Abnormal Child Psychology 39 (2010), pp. 213-224.

10 Ibid., p. 213.

${ }^{11}$ Werner, “Children and War: Risk, Resilience, and Recovery,” pp. 553-558.

12 V. Khamis, "Child Psychological Maltreatment in Palestinian Families," Child Abuse and Neglect 24(8) (2000), pp. 1047-1059.

${ }^{13}$ N. Shalhoub-Kevorkian, "Negotiating the Present, Historicizing the Future: Palestinian Children Speak About the Israeli Separation Wall,” American Behavioral Scientist 49 (2006), pp. 11011124.

${ }^{14}$ Gallagher et al., "Perspectives and Possibilities,” pp. 63-77; K. Harland, Acting Tough: Young Men, Masculinity and the Development of Practice in Northern Ireland (Belfast: Nowhere Man Press, 2009).

15 R. McClelland, The Bamford Review of Mental Health and Learning Disability (Northern Ireland): A Vision of a Comprehensive Child and Adolescent Mental Health Service (Belfast, July 2006); U. Kilkelly, R. Kilpatrick, L. Lundy, L. Moore, P. Scraton, C. Davey, C. Dwyer, and S. McAlister, Children's Rights in Northern Ireland (Belfast: NICCY, 2004).

${ }^{16}$ C. Dwyer, "Risk, Politics and the 'Scientification' of Political Judgement: Prisoner Release and Conflict Transformation in Northern Ireland,” British Journal of Criminology 47 (2007), pp.779_ 797.

${ }^{17}$ Ibid., p. 780.

18 D. Lupton, Risk and Sociocultural Theory: New Directions and Perspectives (Cambridge: Cambridge University Press, 1999), p. 9.

19 A. Giddens, Modernity and Self-Identity: Self and Society in the LateModern Age (Stanford: Stanford University Press, 1991).

20 P. Kelly, "The Dangerousness of Youth-at-Risk: The Possibilities of Surveillance and Intervention in Uncertain Times,” Journal of Adolescence 23 (2000), p. 468.

${ }^{21}$ A. Furlong and F. Cartmel, Young People and Social Change: Individualization and risk in late modernity (Open University Press, 1997), p. 7.

${ }^{22}$ Furlong and Cartmel, Young People and Social Change, p. 8.

${ }^{23}$ Hargie et al., "Constructions of Social Exclusion Among Young People From Interface Areas of Northern Ireland,” p. 873.

24 P. Scraton, "Streets of Terror: Marginalization and Criminalization, and Authoritarian Renewal,” Social Justice 31(1-2) (2004), p. 135.

25 I. Schoon, Risk and Resilience: Adaptions in Changing Times. Cambridge: Cambridge University Press, 2006).

${ }^{26}$ Ibid., p. 5.

${ }^{27}$ Hargie et al., "Constructions of Social Exclusion Among Young People From Interface Areas of Northern Ireland"; Haydon and Scraton, "Conflict, Regulation and Marginalisation in the North of Ireland”; McAlister, "Predictable Pathways?”; McAlister et al., Childhood in Transition.

28 S. McGrellis, "Growing Up in Northern Ireland," London: Joseph Rowntree Foundation (2011);O.Muldoon, "Children of the Troubles: The Impact of PoliticalViolence in Northern Ireland,” Journal of Social Issues 6(3) (2004), pp. 453-468. 
29 J. Garbarino, K. Kostelny, and N. Dubrow, N. "What Can Children Tell Us about Living in Danger,” The American Psychologist 46 (1991), pp. 376-383; M. Leonard, “Trapped in Space? Children's Accounts of Risky Environments,” Children and Society 21 (2007) pp. 432-445.

${ }^{30}$ McAloney, “Damaged Youth,” p. 635.

31 M. Fay, M. Morrissey, M. Smyth, and T. Wong, The Cost of the Troubles Study (Ulster: INCORE, 1999).

32 U. Hansson, Troubled Youth? Young People, Violence and Disorder in Northern Ireland (Belfast: Institute for Conflict Research, 2005), p. 5.

33 E. Cairns, Children and Political Violence (Cambridge, MA: Blackwell, 1996); P. Shirlow, "Who Fears to Speak: Fear, Mobility and Ethno-Sectarianism in the Two Ardoynes," The Global Review of Ethnopolitics 3(1) (2003), pp. 76-91.

${ }^{34}$ M. Smyth, "Remembering in Northern Ireland: Victims, Perpetrators and Hierarchies of Pain and Responsibility," in B. Hamber, ed., Past Imperfect: Dealing with the Past in Northern Ireland and Societies in Transition (Derry, INCORE: 1998), pp. 31-49; K. McEvoy "Law, Struggle and Political Transformation in Northern Ireland,” Journal of Law and Society 27(4) (2000), pp. 542571.

35 D. O’Mahony, R. Geary, K. McEvoy, and J. Morison, Crime, Community and Locale: The Northern Ireand Communities Crime Survey (Aldershot: Ashgate, 2000); K. Harland, "Violent Youth Culture in Northern Ireland: Young Men, Violence, and the Challenges of Peacebuilding," Youth \& Society 43(2) (2010), pp. 414-432.

${ }^{36}$ Eleven of whom died as a direct result of one incident, namely the Omagh bombing, which claimed the lives of the conflicts youngest victims, unborn twins. Source: Conflict Archive on the Internet. Available at www.cain.ulst.ac.uk (10 November 2013).

${ }^{37}$ R. Freel and B. French, Experience of Crime: Findings from the 2006/07 Northern Ireland Crime Survey, Research and Statistical Bulletin, 1/2008 (Belfast: Statistical and Research Branch, Northern Ireland Office, 2008).

${ }^{38}$ N. Jarman, No Longer A Problem?: Sectarian Violence inNorthern Ireland, (Commissioned by Office of the First Minister and Deputy First Minister; OFMDFM) (Belfast: Institute of Conflict Research, 2005).

${ }^{39}$ G. W. Ladd and E. Cairns, (1996) “Children: Ethnic and Political Violence. Introduction,” Child Development 67(1) (1996), p. 15.

${ }^{40}$ Kilkelly et al., Children's Rights in Northern Ireland, p. 244.

${ }^{41}$ McAloney, “Damaged Youth,” p. 635.

${ }^{42}$ D. Hanna, M. Dempster, K. Dyer, E. Lyons, and L. Devaney, Young People’s Transgenerational Issues in Northern Ireland (Belfast: Commission for Victims and Survivors, 2012), p. 69.

${ }^{43}$ P. Shirlow and B. Murtagh, Belfast, Segregation and the City (London: Pluto Press, 2006); F. W. Boal, “Territoriality on the Shankill-Falls divide, Belfast," Irish Geography 6 (1969), pp. 30 50 .

${ }^{44}$ B. Reid, "Labouring towards the Space to Belong: Place and Identity in Northern Ireland,” Irish Geography 37(1) (2004), pp. 103-113.

45 P. Connolly and J.Healy, "The Development of Children'sAttitudes towards the "Troubles" in Northern Ireland,” in O. Hargie, and D. Dickson, eds., Researching the Troubles, Social Science Perspective on the Northern Ireland Conflict (Edinburgh: Mainstream Publishing, 2003), pp. 3758.

${ }^{46}$ Shirlow, "Who Fears to Speak?” p. 78. 
${ }^{47}$ M. Leonard, "Parochial Geographies: Growing Up in Divided Belfast,” Childhood 17(3) (2010), pp. 329-342.

${ }^{48}$ M. Leonard, "Teens and Territory in Contested Spaces: Negotiating Sectarian Interfaces in Northern Ireland,” Children's Geographies 4(2) (2006), pp. 225-238; M. Leonard, 'Trapped in Space? Children’s Accounts of Risky Environments,” Children and Society 21 (2007), pp. 432 445; M. Leonard, "Building, Bolstering and Bridging Boundaries: Teenagers' Negotiations of Interface Areas in Belfast,” Journal of Ethnic and Migration Studies 34(3) (2008), pp. 471-489; N. Jarman and C. O'Halloran, "Recreational Rioting: Young People, Interface Areas and Violence," Child Care in Practice 7(1) (2008), pp. 2-16; J. Byrne, U. Hansson, and J. Bell, Shared Living: Mixed Residential Communities in Northern Ireland (Belfast: Institute for Conflict Research, 2006).

${ }^{49}$ Leonard, "Trapped in Space?,” p. 432.

${ }^{50}$ Leonard, "Parochial Geographies,” p. 329.

${ }^{51}$ Scraton, "Conflict, Regulation and Marginalisation in the North of Ireland," pp. 59- 78; Leonard, “Trapped in Space?” pp. 432-445.

${ }^{52}$ Leonard, "Parochial Geographies,” p. 38.

53 Jarman and O’Halloran, “Recreational Rioting,” p. 2.

${ }^{54}$ A. Smith, "Citizenship Education in Northern Ireland: Beyond National Identity?," Cambridge Journal of Education 33(1) (2003), pp. 15-31.

${ }^{55}$ Haydon and Scraton, "Conflict, Regulation and Marginalisation in the North of Ireland"; McAlister, Scraton, and Haydon, Childhood in Transition.

${ }^{56}$ O. T. Muldoon, K. Mclaughlin, N. Rougier, and K. Trew, "Adolescents' Explanations for Paramilitary Involvement,” Journal of Peace Research 45(5) (2008), pp. 681-695.

${ }^{57}$ K. Harland, "Violent Youth Culture in Northern Ireland: Young Men, Violence, and the Challenges of Peacebuilding," Youth \& Society 43(2) (2010), pp. 414-432.

${ }_{58}^{58}$ Muldoon et al., "Adolescents' Explanations for Paramilitary Involvement."

${ }^{59}$ McAloney, "Damaged Youth,” p. 643.

${ }^{60}$ O. Muldoon, "Children of the Troubles: The Impact of Political Violence in Northern Ireland," Journal of Social Issues 6(3) (2004), p. 465.

${ }^{61}$ Hargie et al., "Constructions of Social Exclusion Among Young People From Interface Areas of Northern Ireland," p. 873.

${ }^{62}$ T. Burchardt, J. LeGrand, and D. Piachaud, "Social Exclusion in Britain," Social Policy and Administration 33 (1999), pp. 227-244.

${ }^{63}$ Gallagher et al., "Perspectives and Possibilities."

64 "Severe Child Poverty in Northern Ireland, Save the Children - February 2011," London: Save the Children, 2011. Available at http://www.savethechildren.org.uk/sites/default/ (accessed 21 July 2014).

${ }^{65}$ P. Hillyard, B. Rolston, andM. Tomlinson, Poverty and Conflict in Ireland: An International Perspective (Dublin: Institute of Public Administration/Combat Poverty Agency, 2005), p. xx.

${ }^{66}$ Kilkelly et al., Children's Rights in Northern Ireland, p. 245.

${ }^{67}$ Belfast Interfaces: Security Barriers and Defensive Use of Space. Belfast Interface Project (November 2011).

${ }^{68}$ P. Nolan, Northern Ireland Peace Monitoring Report: Number Two (Belfast: Community Relations Council, 2013).

${ }^{69}$ Ibid. 
${ }^{70}$ A further point to highlight at this stage is the community differential that points to the fact that out of the top 20 most deprived wards across Northern Ireland, 16 are classified as predominantly Catholic; Nolan, Northern Ireland Peace Monitoring Report, p. 93.

${ }^{71}$ Nolan, Northern Ireland Peace Monitoring Report.

72 Ibid

${ }^{73}$ http://www.ninis2.nisra.gov.uk/public/home.aspx (accessed, 25 May 2013).

${ }^{74}$ A. Self, J. Thomas, and C. Randall, “Measuring National Well-Being: Life in the UK,” London: Office for National Statistics (2012).

75 M. Tomlinson, "War, Peace, and Suicide: The Case of Northern Ireland," International Sociology 27(4) (2012), pp. 464-482.

${ }^{76}$ Ibid, p. 464.

${ }^{77}$ Nolan, Northern Ireland Peace Monitoring Report: Number Two, p. 118.

${ }^{78}$ Haydon and Scraton, “Conflict, Regulation and Marginalisation in the North of Ireland,” p. 65.

${ }^{79}$ Hanna et al., Young People’s Transgenerational Issues in Northern Ireland, p. 70.

${ }^{80}$ D. Bell, “Acts of Union: Youth Subculture and Ethnic Diversity amongst Protestants in Northern Ireland,” British Journal of Sociology 34(3) (1987), p. 159.

81 D. Bell, D. Acts of Union: Youth Culture and Sectarianism in Northern Ireland (London: Macmillan, 1990).

${ }^{82}$ Nirmal Kumar Bose, Selections from Gandhi (Ahmedabad: Navajivan Publishing House, 1948). 